\title{
Red Palm Oil Supplementation Does Not Increase Blood Glucose or Serum Lipids Levels in Wistar Rats With Different Thyroid Status
}

\section{H. RAUCHOVÁ ${ }^{1}$, M. VOKURKOVÁ ${ }^{1}$, S. PAVELKA ${ }^{1}$, I. VANĚČKOVÁ ${ }^{1}$, N. TRIBULOVÁ ${ }^{2}$, T. SOUKUP ${ }^{1}$}

${ }^{1}$ Institute of Physiology of the Czech Academy of Sciences, Prague, Czech Republic, ${ }^{2}$ Institute for Heart Research, Slovak Academy of Sciences, Bratislava, Slovak Republic

Received November 12, 2017

Accepted December 28, 2017

On-line January 5, 2018

\section{Summary}

Red palm oil (RPO) is a rich natural source of antioxidant vitamins, namely carotenes, tocopherols and tocotrienols. However, it contains approximately $50 \%$ saturated fatty acids the regular consumption of which could negatively modify lipid profile. The aim of our study was to test whether 7 weeks of RPO supplementation ( $1 \mathrm{~g} / \mathrm{kg}$ body weight/day) would affect blood glucose and lipid metabolism in adult male Wistar rats with altered thyroid status. We induced hypothyroidism and hyperthyroidism in rats by oral administration of either methimazole or mixture of thyroid hormones. Different thyroid status (EU - euthyroid, HY - hypothyroid and HT - hyperthyroid) was characterized by different serum thyroid hormones levels (total and free thyroxine and triiodothyronine), changes in the activity of a marker enzyme of thyroid status - liver mitochondrial glycerol-3-phosphate dehydrogenase, and altered absolute and relative heart weights. Fasting blood glucose levels were higher in HT rats in comparison with EU and HY rats, but the changes caused by RPO supplementation were not significant. The achievement of the HY status significantly increased serum levels of total cholesterol, as well as with high-density lipoproteincholesterol and low-density lipoprotein-cholesterol: $2.43 \pm 0.15$, $1.48 \pm 0.09,0.89 \pm 0.08 \mathrm{mmol} / \mathrm{l}$, compared to $\mathrm{EU}: 1.14 \pm 0.06$, $0.77 \pm 0.06,0.34 \pm 0.05 \mathrm{mmol} / \mathrm{l}$ and HT: $1.01 \pm 0.06,0.69 \pm 0.04$, $0.20 \pm 0.03 \mathrm{mmol} / \mathrm{l}$, respectively. RPO supplementation did not increase significantly levels of blood lipids but tended to increase glutathione levels in the liver. In conclusion, RPO supplementation did not induce the presumed deterioration of glucose and lipid metabolism in rats with three well-characterized alterations in thyroid status.

\section{Key words}

Hypothyroidism - Hyperthyroidism • Heart • Cholesterol • Glutathione

\section{Corresponding author}

H. Rauchová, Institute of Physiology of the Czech Academy of Sciences, Vídeňská 1083, 14220 Prague 4, Czech Republic. Fax: +420/2/41062488. E-mail: Hana.Rauchova@fgu.cas.cz

\section{Introduction}

Many African and Asian countries consider beneficial health effects of red palm oil (RPO), which is derived from mesocarp of the fruit of the palm oil (Elaeis guineensis). RPO contains high amounts of natural fat-soluble antioxidants such as carotenes, tocopherols and tocotrienols (Sambanthamurthi et al. 2000). This is analogous to the beneficial role of dietary long-chain n-3 polyunsaturated fatty acids (n-3 PUFA) (Pirillo and Catapano 2013, Rauch and Senges 2012). The present $\alpha$-, $\beta$ - and $\gamma$-carotenes show provitamin A activity in RPO effects overcoming vitamin A deficiency (Loganathan et al. 2017). Tocotrienols found in RPO may be beneficial due to their inhibition of endogenous cholesterol biosynthesis in both humans (Qureshi et al. 1991) and animals (Pearce et al. 1992). Moreover, studies of van Rooyen group with RPO in various rat models indicated an improvement of cardiac function after ischemia or ischemia-reperfusion injury (Esterhuyse et al. 2005, Kruger et al. 2007, van Rooyen et al. 2008), a reduction of myocardial infarct size (Bester et al. 2010b, Szucs et 
al. 2011) and a heart protection against the cytotoxic effects of daunorubicin, a strong chemotherapeutic of the anthracycline family (Wergeland et al. 2011). Furthermore, we have shown that RPO intake in male Wistar rats resulted in heart rate decrease and partly ameliorated ventricular fibrillation probably due to the up-regulation of myocardial electrical coupling protein (Szeiffová et al. 2017). In addition, male spontaneously hypertensive rats (SHR) supplemented with RPO benefited particularly due to its apparent antiarrhythmic effect, which was associated predominantly with up-regulation of cardiac connexin-43 (Bačová et al. 2012, Egan Benova et al. 2016).

On the other hand, RPO as other palm oils contains almost equal proportions of unsaturated (oleic, linoleic and linolenic) and saturated (e.g. myristic, palmitic and stearic) fatty acids but not essential n-3 PUFA such as eicosapentaenoic acid (EPA) and docosahexaenoic acid (DHA) (Bester et al. 2010a). Therefore, the principal objection against its consumption is the fact that it can raise the level of blood cholesterol and, concurrently, it might increase the risk of coronary heart disease (Chen et al. 2011, Sun et al. 2015).

Thyroid hormones have wide-ranging effects on cellular development, growth, differentiation and metabolic processes practically in all organ systems. Thyroid hormones strongly influence synthesis, mobilization and degradation of carbohydrates, proteins and lipids. Changes in lipid metabolism associated with thyroid hormones status are well-known nearly 90 years (Mason et al. 1930). Generally, in humans, hypothyroidism (HY) is associated with increased levels of plasma triglycerides (TG), total cholesterol (TC) and low density lipoprotein cholesterol (LDL). In contrast, hyperthyroidism (HT) is related to decreased levels of plasma TG, TC and LDL.

The aim of our present study was to test whether 7 weeks of RPO supplementation can affect the levels of serum lipids induced in adult male Wistar rats with different thyroid status. We also describe the effects of RPO on thyroid hormones levels and the activity of a marker enzyme of thyroid status, liver mitochondrial glycerol-3-phosphate dehydrogenase (GPDH), on blood glucose and the levels of reduced glutathione (GSH) in the liver and kidney, as well as on the body and heart weight changes in these rats.

\section{Materials and Methods}

\section{Reagents}

RPO (Carotino Sdn Bhd, Johor Bahru, Malaysia) was a generous gift from Prof. van Rooyen, Cape Peninsula University of Technology, Faculty of Health and Wellness Sciences, Department of Biomedical Sciences (Bellville, South Africa). The composition of RPO was as follows (w/w): $51 \%$ total saturated fatty acids (SFA), $38 \%$ total monounsaturated fatty acids (MUFA), and $11 \%$ total polyunsaturated fatty acids (PUFA). The particular components also included (w/w) $1.1 \%$ squalene, $560-1000 \mathrm{ppm}$ vitamin E, $500 \mathrm{ppm}$ carotenoids, and $0.4 \mathrm{mg} / \mathrm{l}$ coenzyme $\mathrm{Q}_{10}$ (Bester et al. 2010a). Tris(hydroxymethyl)aminomethane, EDTA, glycerol-3-phosphate, cytochrome $c$ (horse), L-thyroxine (sodium salt), 3,3',5-triiodo-L-thyronine (sodium salt), methimazole (2-mercapto-1-methylimidazole) and bovine serum albumin (BSA) were purchased from SigmaAldrich Co (USA). Narketan (ketamine hydrochloride) and Xylapan (xylazine hydrochloride) were obtained from Vetoquinol S.A. (France) and Vetoquinol Biowet (Poland), respectively. All other reagents were of the highest purity available commercially.

\section{Animals}

The experiments were carried out in 48 male Wistar rats from the rat-breeding facility of our Institute of Physiology of the Czech Academy of Sciences (CAS) in Prague. The animals were housed at $23 \pm 1{ }^{\circ} \mathrm{C}$ and at $12 / 12 \mathrm{~h}$ light-dark cycle periods with ad libitum access to tap water and conventional laboratory chow Altromin. The maintenance and handling of experimental animals were in compliance with the EU Council Directive 86/609/EEC on Animal Protection and Research Animal Use. The experimental protocols were approved by the Ethical Committee of the Institute of Physiology CAS, Czech Republic (Project of experiment No. 139/2013).

\section{Experimental groups}

Rats aged 9-11 weeks were randomly divided into euthyroid (EU, 16 rats), hypothyroid (HY, 16 rats) and hyperthyroid (HT, 16 rats) groups. The HY status was induced and maintained with a $0.05 \%$ solution of methimazole in tap drinking water; and the HT status by a daily administration of the mixture of $16.7 \mu \mathrm{g}$ of L-thyroxine $\left(\mathrm{T}_{4}\right)$ plus $3.3 \mu \mathrm{g}$ of 3,3',5-triiodo-L-thyronine $\left(\mathrm{T}_{3}\right) / 100 \mathrm{~g}$ body weight in tap drinking water. RPO 
( $1 \mathrm{~g} / \mathrm{kg}$ body weight/day) was administered orally to one-half of experimental rats, starting one week before HT and HY status was induced. Then RPO, and methimazole or thyroid hormones were further administered for the following 6 weeks, as described earlier (Szeiffová et al. 2017).

\section{Sample preparation}

At the end of the experiment (after overnight fasting), blood glucose was measured using the EasyGluco system (Infopia Co. Ltd, Anyang, South Korea). The animals were sacrificed by an overdose of the anesthetic Narketan $(0.10 \mathrm{~g} / \mathrm{kg}$ body weight $)$ followed by the myorelaxant Xylapan $(0.01 \mathrm{~g} / \mathrm{kg}$ body weight $)$. After blood collection, heart, kidney and liver were quickly excised and were used for tissue analysis. Pieces of livers were as immediately processed for mitochondria isolation. Samples of kidney and liver were also taken for the measurement of thiols concentration. Sera were prepared by centrifugation of clotted blood samples for $15 \mathrm{~min}$ (ca. 1,300 x g), aliquoted and stored at $-80^{\circ} \mathrm{C}$ until further analysis.

\section{Liver mitochondria isolation}

The excised livers were cleaned, freed of connective tissue and gently homogenized in a glass Teflon homogenizer in ice-cold $250 \mathrm{mM}$ sucrose, $10 \mathrm{mM}$ Tris- $\mathrm{HCl}$ and $1 \mathrm{mM}$ EDTA ( $\mathrm{pH} 7.4)$. The mitochondrial fraction was isolated by differential centrifugation of $10 \%$ homogenate at $4{ }^{\circ} \mathrm{C}$ as described earlier (Johnson and Lardy 1967). Mitochondrial proteins were determined using BSA as a standard (Lowry et al. 1951).

\section{Mitochondrial glycerol-3-phosphate dehydrogenase assay}

The enzyme activity of liver mitochondrial glycerol-3-phosphate dehydrogenase (GPDH) was measured spectrophotometrically at $550 \mathrm{~nm}$ at room temperature following the reduction of cytochrome $c$ (as glycerol-3-phosphate cytochrome $c$ reductase) as described earlier (Rauchová et al. 2004). The protein concentration was approximately $0.1 \mathrm{mg} / \mathrm{ml}$ per cuvette. The results were expressed as nmol of reduced cytochrome $\mathrm{c} / \mathrm{min} / \mathrm{mg}$ of protein using an extinction coefficient of $\varepsilon_{550}=19 \mathrm{mM}^{-1} \mathrm{~cm}^{-1}$.

\section{Biochemical parameters}

Concentrations of plasma lipids, such as triglycerides (TG), total cholesterol (TC), and highdensity lipoprotein-cholesterol (HDL), were estimated using commercial kits (Pliva-Lachema Diagnostika, Brno, Czech Republic) according to the manufacturer's recommendations. Low-density lipoprotein-cholesterol (LDL) was estimated indirectly using the concentrations relation: $\mathrm{LDL}=\mathrm{TC}-(\mathrm{TG} / 5)-\mathrm{HDL}$. Serum concentrations of total $\left(\mathrm{tT}_{3}\right)$ and free $\left(\mathrm{fT}_{3}\right)$ triiodothyronine and total $\left(\mathrm{tT}_{4}\right)$ and free $\left(\mathrm{fT}_{4}\right)$ thyroxine were determined radioimmunologically using commercial RIA kits (Immunotech-Beckman Coulter Co., Prague, Czech Republic) for human and rat sera (Pavelka 2014). The intracellular content of reduced glutathione (GSH) in the fresh liver and kidney was determined according to Ellman (1959). Shortly, the tissue samples were homogenized in $3 \%$ sulfosalicylic acid and $10 \%$ homogenates were centrifuged for $10 \mathrm{~min}$ at $3,000 \mathrm{xg}$. A portion of the supernatant was mixed with $0.02 \mathrm{M}$ 5,5'-dithiobis-(2-nitrobenzoic acid) in $0.1 \mathrm{M}$ phosphate buffer $(\mathrm{pH} 8)$ and the absorbance of a colored product was measured spectrophotometrically at $412 \mathrm{~nm}$. The concentration of GSH was calculated from a calibration curve prepared by serial dilutions of $1 \mathrm{mM}$ stock solution. The results were expressed as $\mu \mathrm{mol} \mathrm{GSH} / \mathrm{g}$ tissue.

\section{Statistical analysis}

Data were expressed as the means \pm SEM and the statistical differences among EU, HY and HT groups were evaluated using one-way analysis of variance (ANOVA). Differences among groups without (untreated) and with RPO supplementation were analyzed using the T-test. Values were considered as statistically significant when $\mathrm{P} \leq 0.05$.

\section{Results}

Thyroid status estimation, body and heart weights, and blood glucose levels

The oral administration of methimazole or thyroid hormones induced HY or HT status, respectively (Table 1). Statistical evaluation revealed highly significant differences in $\mathrm{tT}_{4}$ among all studied groups according to their thyroid status. $\mathrm{tT}_{3}$ was different between HY and HT status both in RPO-untreated and RPO-supplemented rats. In RPO-untreated rats free $\mathrm{T}_{3}$ and free $\mathrm{T}_{4}$ levels were significantly different between HY and HT status while they were significantly different among all groups after RPO supplementation. We found no differences in corresponding parameters between RPO-untreated and RPO-supplemented rats of the same thyroid status. 
Table 1. Studied groups of Wistar rats with different thyroid status.

\begin{tabular}{|c|c|c|c|c|}
\hline & \multirow{2}{*}{ Diet } & \multicolumn{3}{|c|}{ Thyroid status } \\
\hline & & $\mathbf{E U}$ & HY & HT \\
\hline Serum tT3 & $-\mathrm{RPO}$ & $0.87 \pm 0.24$ & $0.59 \pm 0.13$ & $2.39 \pm 0.51 \#$ \\
\hline$($ nmol/l) & $+\mathrm{RPO}$ & $0.88 \pm 0.17$ & $0.63 \pm 0.13$ & $2.90 \pm 0.67 \#$ \\
\hline Serum tT4 & $-\mathrm{RPO}$ & $39.9 \pm 7.09$ & $10.5 \pm 2.13^{*}$ & $94.4 \pm 14.2 * \#$ \\
\hline (nmol/l) & $+\mathrm{RPO}$ & $43.6 \pm 6.53$ & $17.1 \pm 2.85^{*}$ & $84.5 \pm 11.8 * \#$ \\
\hline Serum fT3 & $-\mathrm{RPO}$ & $7.50 \pm 1.55$ & $1.74 \pm 0.10$ & $19.5 \pm 3.78 \#$ \\
\hline (pmol/l) & $+\mathrm{RPO}$ & $7.67 \pm 0.94$ & $1.54 \pm 0.22 *$ & $21.0 \pm 3.41 * \#$ \\
\hline Serum fT4 & $-\mathrm{RPO}$ & $16.5 \pm 1.80$ & $3.60 \pm 0.01$ & $25.8 \pm 2.70 \#$ \\
\hline (pmol/l) & $+\mathrm{RPO}$ & $17.2 \pm 0.80$ & $2.90 \pm 0.70 *$ & $26.4 \pm 2.10 * \#$ \\
\hline GPDH activity & $-\mathrm{RPO}$ & $7.42 \pm 0.75$ & $4.65 \pm 0.72$ & $28.5 \pm 7.41 * \#$ \\
\hline (nmol/min/mg protein) & $+\mathrm{RPO}$ & $8.29 \pm 0.42$ & $4.72 \pm 0.65$ & $30.2 \pm 5.81 * \#$ \\
\hline
\end{tabular}

All values are mean $\pm \mathrm{SEM}$. Significantly different: $* P \leq 0.05$ vs. EU status; ${ }^{*} P \leq 0.05$ vs. HY status. EU, euthyroid status; $\mathrm{HY}$, hypothyroid status; $\mathrm{HT}$, hyperthyroid status; RPO, red palm oil; $\mathrm{tT}_{3}$, total triiodothyronine; $\mathrm{fT}_{3}$, free triiodothyronine; $\mathrm{tT}_{4}$, total thyroxine; $\mathrm{fT}_{4}$, free thyroxine; GPDH, glycerol-3-phosphate cytochrome $c$ reductase activity.

Table 2. Body weight, absolute and relative heart weights and blood glucose levels in rats with different thyroid status.

\begin{tabular}{|c|c|c|c|c|}
\hline & \multirow{2}{*}{ Diet } & \multicolumn{3}{|c|}{ Thyroid status } \\
\hline & & $\mathbf{E U}$ & HY & HT \\
\hline Body weight & $-\mathrm{RPO}$ & $417 \pm 27$ & $397 \pm 7$ & $404 \pm 17$ \\
\hline$(B W ; g)$ & $+\mathrm{RPO}$ & $423 \pm 21$ & $394 \pm 21$ & $405 \pm 16$ \\
\hline Absolute heart weight & $-\mathrm{RPO}$ & $1120 \pm 90$ & $836 \pm 50^{*}$ & $1465 \pm 90 * \#$ \\
\hline$(H W ; m g)$ & $+\mathrm{RPO}$ & $1145 \pm 30$ & $772 \pm 30 *$ & $1352 \pm 60^{* \#}$ \\
\hline Relative heart weight & $-\mathrm{RPO}$ & $2.8 \pm 0.2$ & $2.1 \pm 0.1 *$ & $3.6 \pm 0.2^{* \#}$ \\
\hline$(H W / B W)$ & $+\mathrm{RPO}$ & $2.6 \pm 0.1$ & $2.2 \pm 0.2 *$ & $3.3 \pm 0.2 *^{\#}$ \\
\hline Fasting glucose & $-\mathrm{RPO}$ & $4.4 \pm 0.2$ & $4.1 \pm 0.4$ & $6.2 \pm 0.1^{\#}$ \\
\hline$(\mathrm{mmol} / \mathrm{l})$ & $+\mathrm{RPO}$ & $5.2 \pm 0.2$ & $4.5 \pm 0.3$ & $5.9 \pm 0.4$ \\
\hline
\end{tabular}

All values are mean \pm SEM. Significantly different: * $P \leq 0.05$ vs. EU status; ${ }^{*} P \leq 0.05$ vs. HY status. EU, euthyroid status; $\mathrm{HY}$, hypothyroid status; HT, hyperthyroid status; RPO, red palm oil.

The activity of liver mitochondrial GPDH was decreased in the HY rats by about one half and increased in the HT rats about three times compared to EU status, irrespective of RPO supplementation. The GPDH activity differed significantly between HY and HT status, in both RPO-untreated and RPO-supplemented groups. RPO supplementation did not lead to significant changes in GPDH activity in any group of the rats (Table 1).

At the end of experiment, i.e. after 7 weeks of RPO supplementation with or without methimazole or thyroid hormones treatment, there were no significant differences in body weights of the rats aged 16-18 weeks (Table 2). Compared with EU, HY status led to a fall in absolute and relative (absolute heart weight/body weight) heart weights, while HT status was characterized by a significant increase in absolute and relative heart weights. RPO supplementation non-significantly reduced the increase of absolute heart weight observed in rats with HT status. However, RPO also non-significantly attenuated the absolute heart weight decrease observed in rats with in HY status (Table 2). 
Table 3. Lipid characteristics of rats with different thyroid status.

\begin{tabular}{lcccc}
\hline & Diet & \multicolumn{3}{c}{ Thyroid status } \\
\cline { 3 - 5 } & & EU & HY & HT \\
\hline Serum triglycerides & $-\mathrm{RPO}$ & $0.45 \pm 0.04$ & $0.33 \pm 0.05$ & $0.46 \pm 0.05$ \\
(mmol/l) & $+\mathrm{RPO}$ & $0.58 \pm 0.03$ & $0.38 \pm 0.06$ & $0.44 \pm 0.05$ \\
Total cholesterol & $-\mathrm{RPO}$ & $1.14 \pm 0.06$ & $2.43 \pm 0.15^{*}$ & $1.01 \pm 0.06^{\#}$ \\
(mmol/l) & $+\mathrm{RPO}$ & $1.24 \pm 0.06$ & $2.20 \pm 0.18^{*}$ & $1.11 \pm 0.10^{\#}$ \\
HDL & $-\mathrm{RPO}$ & $0.77 \pm 0.06$ & $1.48 \pm 0.09^{*}$ & $0.69 \pm 0.04^{\#}$ \\
(mmol/l) & $+\mathrm{RPO}$ & $0.79 \pm 0.05$ & $1.32 \pm 0.14^{*}$ & $0.79 \pm 0.08^{\#}$ \\
LDL & $-\mathrm{RPO}$ & $0.34 \pm 0.05$ & $0.89 \pm 0.08^{*}$ & $0.20 \pm 0.03^{\#}$ \\
(mmol/l) & $+\mathrm{RPO}$ & $0.30 \pm 0.03$ & $0.84 \pm 0.09^{*}$ & $0.27 \pm 0.03^{\#}$ \\
TC/HDL & $-\mathrm{RPO}$ & $1.51 \pm 0.09$ & $1.65 \pm 0.06$ & $1.49 \pm 0.09$ \\
$($ ratio $)$ & $+\mathrm{RPO}$ & $1.60 \pm 0.09$ & $1.71 \pm 0.08$ & $1.43 \pm 0.05$ \\
\hline
\end{tabular}

All values are mean $\pm \mathrm{SEM}$. Significantly different: $* P \leq 0.05$ vs. EU status; ${ }^{*} P \leq 0.05$ vs. HY status. EU, euthyroid status; HY, hypothyroid status; HT, hyperthyroid status; HDL, high-density lipoprotein-cholesterol; LDL, low-density lipoprotein-cholesterol; TC, total cholesterol; RPO, red palm oil.

Table 4. Concentration of thiol groups in the liver and kidney of rats with different thyroid status.

\begin{tabular}{lcccc}
\hline & Diet & \multicolumn{3}{c}{ Thyroid status } \\
\cline { 3 - 5 } & & EU & HY & HT \\
\hline SH in the liver & $-\mathrm{RPO}$ & $5.11 \pm 0.36$ & $6.73 \pm 0.21$ & $5.05 \pm 0.46$ \\
$(\mu \mathrm{mol} / \mathrm{g})$ & $+\mathrm{RPO}$ & $6.32 \pm 0.47$ & $9.61 \pm 1.10^{*}$ & $5.06 \pm 0.23^{\#}$ \\
SH in the kidney & $-\mathrm{RPO}$ & $3.10 \pm 0.27$ & $3.70 \pm 0.06$ & $3.03 \pm 0.66$ \\
$(\mu \mathrm{mol} / \mathrm{g})$ & $+\mathrm{RPO}$ & $3.26 \pm 0.14$ & $3.78 \pm 0.27$ & $3.55 \pm 0.08$ \\
\hline
\end{tabular}

All values are mean \pm SEM. Significantly different: * $P \leq 0.05$ vs. EU status; \# $P \leq 0.05$ vs. HY status. EU, euthyroid status; $\mathrm{HY}$, hypothyroid status; HT, hyperthyroid status; SH, thiol groups; RPO, red palm oil.

Fasting blood glucose levels were decreased in $\mathrm{HY}$ and increased in HT groups compared to EU status in both RPO-untreated and RPO-supplemented rats. However, the difference between HY and HT groups was significant only in the RPO-untreated rats. RPO supplementation had only negligible effects: fasting glucose level was increased by $7 \%$ and $10 \%$ in the EU and HY rats, respectively, and decreased by $4 \%$ in the HT rats. Nevertheless, the RPO supplementation abolished the significance of this difference due to increased glucose level in rats with HY status and decreased glucose level in rats with HT status (Table 2).

\section{Lipids levels estimation}

HY status was associated with significantly increased TC, concurrently with elevated HDL and LDL, regardless of RPO supplementation (Table 3). On the other hand, TC values in HT rats were significantly decreased in comparison with HY rats, but the difference did not reach statistical significance compared to EU rats. In contrast, fasting TG were not elevated in $\mathrm{HY}$ rats (regardless of RPO supplementation).

We found similar values of HDL levels, regardless of RPO supplementation, which were significantly increased in HY rats, while they were unchanged in HT rats compared to rats in EU status. Similarly, calculated LDL values corresponded well to $\mathrm{TC}$ and HDL values, i.e. they were significantly increased in HY and rather decreased in HT groups. Calculated atherogenic index (TC/HDL) slightly (but not significantly) increased in RPO-untreated as well as in RPO-supplemented HY rats, and decreased in HT rats, in 
comparison with EU groups.

\section{Determination of thiols concentrations}

Concentrations of reduced form of GSH in the liver followed the thyroid status of the rats as summarized in Table 4. We found higher values in the liver of RPOuntreated HY rats and lower values in HT rats. RPO supplementation accentuated liver changes in HY group in comparison with both EU and HT groups, so that these differences became significant. GSH levels in the kidney were only slightly affected by alterations of thyroid status (Table 4).

\section{Discussion}

Thyroid status estimation, body and heart weights, and blood glucose levels

In the study, we changed our preceding protocol for inducing HT status in the rats, using oral administration of $\mathrm{T}_{3}$ and $\mathrm{T}_{4}$ combination in drinking water, similarly as was done by Szeiffová et al. (2017). This protocol seems to be more appropriate for the animals as compared to previously applied intraperitoneal administration of $\mathrm{T}_{3}$ only (Rauchová et al. 2004, Rauchová et al. 2013). The serum levels of total and free $\mathrm{T}_{3}$ and $\mathrm{T}_{4}$ in the present study reflected well the achievement of the chronic HY and HT status in the treated rats.

The liver mitochondrial GPDH activity, known as a sensitive $T_{3}$ target gene (Weitzel et al. 2001), showed a good response in both HT and HY groups, regardless of RPO supplementation.

We observed no significant differences in body weight of the rats in three different thyroid groups with or without RPO supplementation. Similarly, our previous studies did not reveal any significant differences in body weights among three experimental groups (EU, HY, HT) of Lewis and Wistar rats with thyroid hormones treatment lasting few weeks, respectively (Rauchová et al. 2013, Szeiffová et al. 2017). Nevertheless, the absolute and relative heart weights clearly demonstrated the influence of thyroid status. HT rats had increased heart weight, what can be considered as an adaptive process serving to compensate for increased hemodynamic load, while pharmacologically induced HY status reduced the heart weight probably due to reduced heart load compared to the EU animals.

The relationship between thyroid hormones levels and blood glucose homeostasis is well-known
(Potenza et al. 2009). Thyroid hormones oppose the action of insulin facilitating glucose disposal and utilization in peripheral tissues (Kapadia et al. 2012). In the present study HT rats manifested signs of hyperglycemia regardless of RPO supplementation. We obtained very similar values of fasting glucose levels in our previous experiments on Lewis rats with altered thyroid status (Rauchová et al. 2013).

\section{Serum lipids levels estimation}

Plasma TC levels can be used as a biological marker of metabolic effects of thyroid hormones in rodent models, however, the TG levels in HY rats could be normal, reduced or marginally elevated (Bianco et al. 2014). Our results clearly reflected the attained thyroid status of the rats concerning TC, HDL and LDL levels. Fasting TG were not significantly different (regardless of RPO supplementation).

Dietary palm oil is obtained from the refined, bleached and deodorized crude palm oil. During these processes a part of carotenoids and tocotrienols is removed. The results of different experimental and clinical studies of effects of various palm oil products as substances raising cholesterol levels are miscellaneous. Fattore et al. (2014) published an extensive systematic review and performed meta-analysis from fifty-one human studies, which included data comparing palm oil-rich diets with other fat-rich diets and analyzed at least one marker related to blood lipids, e.g. TG, TC, LDL, HDL, TC/HDL or LDL/HDL ratios. The authors recorded both favorable and unfavorable changes by following risk markers in comparison with the effects of other primary dietary fat, such as stearic acid, monounsaturated fatty acids or n-3 PUFA. In conclusion, their results did not support a direct link between palm oil substitution and reduction of mortality from cardiovascular diseases. However, favorable changes occurred when trans fatty acids were replaced by palm oil (Fattore et al. 2014). Recently, Loganathan et al. (2017) summarized different health-promoting effects (including antiatherogenic, antihemorrhagic, antihypertensive, anticancer and even anti-infectious properties) of RPO followed from a number of human and animal studies. Oida et al. (2015) reviewed data obtained in laboratory animals as well as in human studies concluding that palm oil consumption did not elevate serum levels of TC and did not increase a risk factor of cardiovascular diseases. Our results are in agreement with these findings because serum TC levels in our experimental rats were not 
significantly changed by RPO supplementation, opposite to changes of thyroid status. LDL levels showed similar changes as TC levels. Correspondingly, 7-week-old male Sprague-Dawley rats after 22-day-supplementation of diet with palm oil ( $2.5 \mathrm{ml}$ palm oil/rat/day) did not show any significant differences in serum lipids levels and cardiac risk index suggesting that added palm oil did not cause hyperlipidemia (Go et al. 2015). However, histological analysis of samples of rat liver tissue revealed some dysfunction of the liver lipid metabolism in comparison with sunflower diet (Go et al. 2015). On the other hand, Mizurini et al. (2011) showed that rats fed diet with palm oil had a less favorable lipid profile with increased TG levels.

\section{Determination of thiol concentrations}

In our study, 7-week-supplementation of RPO only slightly modified GSH levels in both liver and kidney. Ganafa et al. (2002) showed that 5-weeksupplementation of palm oil ( $5 \mathrm{~g} / \mathrm{kg} /$ day) did not change GSH levels in kidney, heart and plasma of male SpragueDawley rats aged 9-10 weeks. However, palm oil supplementation partially increased reduced GSH levels in kidney that were reduced by buthionine sulfoximine (BSO), which is a selective inhibitor of GSH biosynthesis pathway. Nevertheless, palm oil supplementation did not significantly modify the BSO effect in the heart or plasma GSH levels (Ganafa et al. 2002).

\section{Conclusions}

In our study the supplementation of rat's diet with red palm oil at a dose of $1 \mathrm{~g} / \mathrm{kg}$ body weight/day for 7 weeks did not significantly modify blood glucose and lipids levels in rats with different thyroid status. Thus, the intake of RPO with unfavorable fatty acid composition did not induce the presumed deterioration of glucose and cholesterol metabolism.

\section{Conflict of Interest}

There is no conflict of interest.

\section{Acknowledgements}

This work was supported by research grant SAV-CZ 10-03, research grant 15-25396A (Ministry of Health of the Czech Republic) and the research project RVO: 67985823 (Institute of Physiology of the CAS).

Current address of $M$. Vokurková: Institute of Rheumatology, Prague, Czech Republic, e-mail: vokurkova@revma.cz

\section{References}

BAČOVÁ B, RADOŠINSKÁ J, VICZENCZOVÁ C, KNEZL V, DOSENKO V, BEŇOVA T, NAVAROVÁ J, GONÇALVESOVÁ E, VAN ROOYEN J, WEISMANN P, SLEZÁK J, TRIBULOVÁ N: Up-regulation of myocardial connexin-43 in spontaneously hypertensive rats fed red palm oil is most likely implicated in its anti-arrhythmic effects. Can J Physiol Pharmacol 90: 1235-1245, 2012.

BESTER D, ESTERHUYSE AJ, TRUTER EJ, VAN ROOYEN J: Cardiovascular effects of edible oils: a comparison between four popular edible oils. Nutr Res Rev 23: 334-348, 2010a.

BESTER DJ, KUPAI K, CSONT T, SZUCS G, CSONKA C, ESTERHUYSE AJ, FERDINANDY P, VAN ROOYEN J: Dietary red palm oil supplementation reduces myocardial infarct size in an isolated perfused rat heart model. Lipids Health Dis 9: 64, 2010b.

BIANCO AC, ANDERSON G, FORREST D, GALTON VA, GEREBEN B, KIM BW, KOPP PA, LIAO XH, OBREGON MJ, PEETERS RP, REFETOFF S, SHARLIN DS, SIMONIDES WS, WEISS RE, WILLIAMS GR: American thyroid association guide to investigating thyroid hormone economy and action in rodent and cell models. Thyroid 24: 88-168, 2014.

CHEN BK, SELIGMAN B, FARQUHAR JW, GOLDHABER-FIEBERT JD: Multi-country analysis of palm oil consumption and cardiovascular disease mortality for countries at different stages of economic development: 1980-1997. Global Health 7: 45, 2011.

EGAN BENOVA T, SZEIFFOVA BACOVA B, VICZENCZOVA C, DIEZ E, BARANCIK M, TRIBULOVA N: Protection of cardiac cell-to-cell coupling attenuate myocardial remodeling and proarrhythmia induced by hypertension. Physiol Res 65 (Suppl 1): S29-S42, 2016.

ELLMAN GL: Tissue sulfhydryl groups. Arch Biochem Biophys 82: 70-77, 1959. 
ESTERHUYSE AJ, DU TOIT EF, BENADÈ AJ, VAN ROOYEN J: Dietary red palm oil improves reperfusion cardiac function in the isolated perfused rat heart of animals fed a high cholesterol diet. Prostaglandins Leukot Essent Fatty Acids 72: 153-161, 2005.

FATTORE E, BOSETTI C, BRIGHENTI F, AGOSTONI C, FATTORE G: Palm oil and blood lipid-related markers of cardiovascular disease: a systematic review and meta-analysis of dietary intervention trials. Am J Clin Nutr 99: 1331-1350, 2014.

GANAFA AA, SOCCI RR, EATMAN D, SILVESTROV N, ABUKHALAF IK, BAYORH MA: Effect of palm oil on oxidative stress-induced hypertension in Sprague-Dawley rats. Am J Hypertens 15: 725-731, 2002.

GO RE, HWANG KA, KIM YS, KIM SH, NAM KH, CHOI KC: Effects of palm and sunflower oils on serum cholesterol and fatty liver in rats. J Med Food 18: 363-369, 2015.

JOHNSON D, LARDY H: Isolation of liver or kidney mitochondria. Meth Enzymol 10: 94-96, 1967.

KAPADIA KB, BHATT PA, SHAH JS: Association between altered thyroid state and insulin resistance. J Pharmacol Pharmacother 3: 156-160, 2012.

KRUGER MJ, ENGELBRECHT AM, ESTERHUYSE J, DU TOIT EF, VAN ROOYEN J: Dietary red palm oil reduces ischaemia-reperfusion injury in rats fed a hypercholesterolaemic diet. Br J Nutr 97: 653-660, 2007.

LOGANATHAN R, SUBRAMANIAM KM, RADHAKRISHNAN AK, CHOO YM, TENG KT: Health-promoting effects of red palm oil: evidence from animal and human studies. Nutr Rev 75: 98-113, 2017.

LOWRY OH, ROSEBROUGH NJ, FARR AL, RANDALL RJ: Protein measurement with the Folin phenol reagent. J Biol Chem 193: 265-275, 1951.

MASON RL, HUNT HM, HURXTHAL L: Blood cholesterol values in hyperthyroidism and hypothyroidism-their significance. N Engl J Med 203: 1273-1278, 1930.

MIZURINI DM, MAIA IC, SARDINHA FL, MONTEIRO RQ, ORTIZ-COSTA S, DO CARMO MG: Venous thrombosis risk: effects of palm oil and hydrogenated fat diet in rats. Nutrition 27: 233-238, 2011.

ODIA OJ, OFORI S, MADUKA O: Palm oil and the heart: a review. World J Cardiol 7: 144-149, 2015.

PAVELKA S: Development of radiometric assays for quantification of enzyme activities of the key enzymes of thyroid hormones metabolism. Physiol Res 63 (Suppl 1): S133-S140, 2014.

PEARCE BC, PARKER RA, DEASON ME, QURESHI AA, WRIGHT JJ: Hypocholesterolemic activity of synthetic and natural tocotrienols. J Med Chem 35: 3595-3606, 1992.

PIRILLO A, CATAPANO AL: Omega-3 polyunsaturated fatty acids in the treatment of atherogenic dyslipidemia. Atheroscler Suppl 14: 237-242, 2013.

POTENZA M, VIA MA, YANAGISAWA RT: Excess thyroid hormone and carbohydrate metabolism. Endocr Pract 15: 254-262, 2009.

QURESHI AA, QURESHI N, WRIGHT JJ, SHEN Z, KRAMER G, GAPOR A, CHONG YH, DEWITT G, ONG A, PETERSON DM, BRADLOW BA: Lowering of serum cholesterol in hypercholesterolemic humans by tocotrienols (palmvitee). Am J Clin Nutr 53 (4 Suppl): 1021S-1026S, 1991.

RAUCH B, SENGES J: The effects of supplementation with omega-3 polyunsaturated fatty acids on cardiac rhythm: anti-arrhythmic, pro-arrhythmic, both or neither? It depends... Front Physiol 3: 57, 2012.

RAUCHOVÁ H, ZACHAŘOVÁ G, SOUKUP T: Influence of chronically altered thyroid status on the activity of liver mitochondrial glycerol-3-phosphate dehydrogenase in female inbred Lewis rats. Horm Metab Res 36: 286-290, 2004.

RAUCHOVÁ $\mathrm{H}$, VOKURKOVÁ $\mathrm{M}$, PAVELKA S, BEHULIAK $\mathrm{M}$, TRIBULOVÁ $\mathrm{N}$, SOUKUP $\mathrm{T}$ : $\mathrm{N}-3$ polyunsaturated fatty acids supplementation does not affect changes of lipid metabolism induced in rats by altered thyroid status. Horm Metab Res 45: 507-512, 2013.

SAMBANTHAMURTHI R, SUNDRAM K, TAN Y: Chemistry and biochemistry of palm oil. Prog Lipid Res 39: 507-558, 2000.

SUN Y, NEELAKANTAN N, WU Y, LOTE-OKE R, PAN A, VAN DAM RM: Palm oil consumption increases LDL cholesterol compared with vegetable oils low in saturated fat in a meta-analysis of clinical trials. $J$ Nutr $\mathbf{1 4 5}$ : 1549-1558, 2015. 
SZEIFFOVÁ BS, VINCZENZOVÁ C, ŽURMANOVÁ J, KAŠPAROVÁ D, KNEZL V, BEŇOVÁ TE, PAVELKA S, SOUKUP T, TRIBULOVÁ N: Altered thyroid status affects myocardial expression of connexin- 43 and susceptibility of rat heart to malignant arrhythmias that can be partially normalized by red palm oil intake. Histochem Cell Biol 147: 63-73, 2017.

SZUCS G, BESTER DJ, KUPAI K, CSONT T, CSONKA C, ESTERHUYSE AJ, FERDINANDY P, VAN ROOYEN J: Dietary red palm oil supplementation decreases infarct size in cholesterol fed rats. Lipids Health Dis 10: 103, 2011.

VAN ROOYEN J, ESTERHUYSE AJ, ENGELBRECHT AM, DU TOIT EF: Health benefits of a natural carotenoid rich oil: a proposed mechanism of protection against ischaemia/reperfusion injury. Asia Pac J Clin Nutr $\mathbf{1 7}$ (Suppl 1): 316-319, 2008.

WEITZEL JM, KUTZ S, RADTKE C, GROTT S, SEITZ HJ: Hormonal regulation of multiple promoters of the rat mitochondrial glycerol-3-phosphate dehydrogenase gene: identification of a complex hormone-response element in the ubiquitous promoter B. Eur J Biochem 268: 4095-4103, 2001.

WERGELAND A, BESTER DJ, SISHI BJ, ENGELBRECHT AM, JONASSEN AK, VAN ROOYEN J: Dietary red palm oil protects the heart against the cytotoxic effects of anthracycline. Cell Biochem Funct 29: 356-364, 2011. 